\title{
SELETIVIDADE DO S-METOLACHLOR A CULTIVARES DE FEIJÃO (Phaseolus vulgaris L.)
}

\author{
SÉRGIO DE OLIVEIRA PROCÓPIO ${ }^{1}$ \\ ANTÔNIO ALBERTO DA SILVA ${ }^{2}$ \\ JOSÉ BARBOSA DOS SANTOS ${ }^{3}$ \\ JOSÉ IVO RIBEIRO JÚNIOR ${ }^{4}$
}

\begin{abstract}
RESUMO - Realizou-se este trabalho com o objetivo de avaliar a seletividade do herbicida s-metolachlor a cultivares de feijão (Phaseolus vulgaris L.), mediante avaliações realizadas em câmara de crescimento. Os tratamentos foram compostos pelas combinações de seis cultivares de feijão (Carioca, Rudá, Pérola, Jalo Precoce, Vermelho 2157 e Xamego) e de sete doses do s-metolachlor $(0,00 ; 0,48 ; 0,96 ; 1,44 ; 1,92 ; 2,88$ e $3,84 \mathrm{~kg} / \mathrm{ha})$. Verificou-se que a única cultivar que não apresentou diminuição da altura de plantas com o aumento das doses do s-metolachlor foi a Pérola, sendo a cultivar Vermelho 2157 a mais sensível. A única cultivar que apresentou redução da biomassa seca da parte aérea de plantas com a aplicação de doses crescentes do s-metolachlor foi a
\end{abstract}

Carioca. Somente as cultivares Carioca e Jalo Precoce mostraram-se suscetíveis ao s-metolachlor, quanto à redução da biomassa seca das raízes. Contudo, a maior redução dessa característica foi observada para a cultivar Carioca. Todas as cultivares apresentaram aumento no nível de sintomas visuais de toxicidade com o aumento das doses do s-metolachlor. As cultivares Carioca e Vermelho 2157 mostraram-se como as mais sensíveis à ação do smetolachlor, apresentando, respectivamente, aumento de 22,0 e 21,1\% nas injúrias das plantas aos 30 dias após a semeadura, a cada $1 \mathrm{~kg} / \mathrm{ha}$ de s-metolachlor aplicado. As cultivares mais seletivas ao s-metolachlor quanto à exteriorização de sintomas de toxicidade foram a Pérola e a Jalo Precoce.

TERMOS PARA INDEXAÇÃO: Herbicida, tolerância, toxicidade.

\section{S-METOLACHLOR SELECTIVITY TO DRY BEAN (Phaseolus vulgaris L.) CULTIVARS}

\begin{abstract}
The objective of work was to evaluate the selectivity of the s-metolachlor herbicide to dry bean cultivars (Phaseolus vulgaris L.), through evaluations accomplished in growth chamber. The treatments consisted of the combinations of six dry bean cultivars (Carioca, Rudá, Pérola, Jalo Precoce, Vermelho 2157 and Xamego) and seven doses of s-metolachlor (0.00; $0.48 ; 0.96 ; 1.44 ; 1.92 ; 2.88$ and $3.84 \mathrm{~kg} / \mathrm{ha})$. It was verified that the only cultivar that didn't show decrease of the plant height with the increase of s-metolachlor doses was Pérola, and that Vermelho 2157 cultivar was the most sensitive. The only cultivar that showed reduction of the dry matter of the aerial part of plants with the application of increasing doses of $\mathrm{s}$ -
\end{abstract}

metolachlor was the Carioca. Carioca and Jalo Precoce cultivars were susceptible to s-metolachlor, regarding the reduction of the roots dry matter. However, the largest reduction in this characteristic was observed in Carioca. The level of visual symptoms of toxicity increased for all cultivars with the increase of doses. The Carioca and Vermelho 2157 were the most sensitive to action of s-metolachlor, presenting, respectively, increase of 22.0 and $21.1 \%$ in the injuries of plants at 30 days after the planting, to each $1 \mathrm{~kg} / \mathrm{ha}$ of s-metolachlor applied. The cultivars more selective to the s-metolachlor with regard to the toxicity symptoms were Pérola and Jalo Precoce.

INDEX TERMS: Herbicide, tolerance, toxicity.

1. Engenheiro Agrônomo, Doutorando Departamento de Fitotecnia, UFV, Av. PH Rolfs s/n; 36571-000 -Viçosa, MG. procopio@alunos.ufv.br.

2. Engenheiro Agrônomo, Doutor, Professor Departamento de Fitotecnia da UFV, Viçosa, MG.

3. Engenheiro Agrônomo, Mestrando, Departamento de Fitotecnia, UFV, Viçosa, MG.

4. Engenheiro Agrônomo, Doutor, Professor Departamento de Informática da UFV, Viçosa, MG. 


\section{INTRODUÇÃO}

O herbicida metolachlor vem sendo utilizado há mais de 20 anos em mais de 70 diferentes culturas agrícolas em todo o mundo como herbicida seletivo (O’Connell et al., 1998). Esse produto controla com eficiência diversas plantas daninhas gramíneas e algumas dicotiledôneas, sendo aplicado em pré-emergência. O metolachlor consiste de dois R-isômeros e dois Sisômeros, presentes em iguais proporções no produto comercial. Contudo, os S-isômeros são os que propiciam maior atividade herbicida. Um ajuste interno no processo de fabricação desse herbicida permitiu um enriquecimento de $\mathrm{S}$-isômeros (acima de $80 \%$ ) na formulação comercial, sendo, então, criado o s-metolachlor (O’Connell et al., 1998). Esse novo produto apresenta as mesmas características do metolachlor, inclusive a mesma eficiência e seletividade; todavia, com redução de aproximadamente $35 \%$ na dose aplicada ( $\mathrm{O}^{\prime}$ Connell et al., 1998). O maior benefício, advindo dessa mudança tecnológica, é a redução no lançamento de agroquímicos no meio ambiente, seja de ingrediente ativo, seja de componentes da formulação.

A expansão da cultura do feijão no Brasil, principalmente no "cultivo de inverno", com alto consumo de insumos agrícolas, alavancou o crescimento do uso de herbicidas no manejo das plantas daninhas nessa cultura. Entre os vários herbicidas aplicados nessa cultura, destaca-se o metolachlor, não só pela eficiência comprovada, mas também por ser um importante produto no manejo da resistência das plantas daninhas a herbicidas, pois ainda não há nenhum caso de resistência comprovada no mundo envolvendo o metolachlor, ou mesmo outro herbicida pertencente a seu grupo químico (cloroacetamidas). Entretanto, a ocorrência esporádica de perda de seletividade desse produto à cultura do feijão (fitotoxicidade) preocupa em relação à sua permanência nesse mercado. Vários fatores podem estar associados às injúrias causadas pelo herbicida às plantas de feijão, entre eles a diversidade na sensibilidade entre as cultivares utilizadas comercialmente no País. Machado Neto et al. (1988) verificaram apenas leve toxicidade do metolachlor às cultivares de feijão Carioca, Carioca 80 , Roxinho, Bolinha, Carnaval e Rio Negro. Rodrigues et al. (1984) observaram que o metolachlor causou toxicidade à cultivar de feijão Rio Tibagi, não havendo, porém, prejuízo ao rendimento de grãos. Fuentes et al. (1984) detectaram menor tolerância das cultivares de feijão Ricobaio 1014 e Ricopardo 896, em relação às cultivares Negrito 897 e Costa Rica à aplicação do alachlor.

O objetivo com este trabalho foi avaliar a seletividade do s-metolachlor aplicado em sete diferentes doses, a seis cultivares de feijão, sob condições controladas.

\section{MATERIAL E MÉTODOS}

$\mathrm{O}$ experimento foi conduzido em câmara de crescimento, regulada para fotoperíodo de $12 \mathrm{~h}$, temperatura média de $29 / 20 \pm 3^{\circ} \mathrm{C}$ (dia/noite) e $300 \mu \mathrm{mol}$ de fótons $/ \mathrm{m}^{2} \mathrm{~s}$ (Radiação Fotossinteticamente Ativa RFA). Os tratamentos foram compostos pelas combinações de seis cultivares de feijão (Carioca, Rudá, Pérola, Jalo Precoce, Vermelho 2157 e Xamego) e de sete doses do s-metolachlor $(0,00 ; 0,48 ; 0,96 ; 1,44 ; 1,92 ; 2,88$ e $3,84 \mathrm{~kg} / \mathrm{ha}$ ), totalizando-se 42 tratamentos. O delineamento experimental utilizado foi o inteiramente casualizado em esquema fatorial $(6 \times 7)$, com quatro repetições.

Após a obtenção das sementes, essas foram selecionadas e semeadas em caixas gerbox $(10 \times 10 \times 3 \mathrm{~cm})$, preenchidas com solo homogeneizado, cujas características física e química encontram-se na Tabela 1.

TABELA 1 - Características físicas e químicas do solo utilizado no experimento de seletividade do s-metolachlor a cultivares de feijão. Viçosa - MG, 2001.

\section{Análise granulométrica}

Análise química

\begin{tabular}{|c|c|c|c|c|c|c|c|c|}
\hline \multirow[t]{2}{*}{ Solo utilizado } & Argila & Silte & Areia fina & Areia grossa & $\mathbf{t}$ & $\mathbf{T}$ & MO & \multirow{2}{*}{$\begin{array}{c}\mathrm{pH} \\
\mathrm{H}_{2} \mathrm{O}\end{array}$} \\
\hline & \multicolumn{4}{|c|}{$\mathrm{dag} / \mathrm{kg}$} & \multicolumn{2}{|c|}{$\mathrm{cmolc} / \mathrm{dm}^{3}$} & $\mathrm{dag} / \mathrm{kg}$ & \\
\hline Areia Quartzosa & 16 & 29 & 20 & 35 & 1,18 & 2,58 & 1,90 & 5,90 \\
\hline
\end{tabular}

Análises realizadas nos Laboratórios de Análises Físicas e Químicas de Solo do Departamento de Solos da UFV, segundo a metodologia da EMBRAPA (1997). 
Em cada gerbox foram semeadas três sementes de feijão na profundidade de $1,5 \mathrm{~cm}$. Finalizada essa etapa, foi realizada a aplicação do s-metolachlor no topo dos recipientes, utilizando-se um pulverizador de precisão, regulado para se obter volume de aplicação de 200 L/ha. Após a semeadura e aplicação do s-metolachlor, manteve-se o substrato em todas as parcelas com mesmo teor de água (próximo à capacidade de campo) até a colheita do experimento aos 30 dias após a semeadura (DAS).

Para propiciar um bom desenvolvimento das plantas, foi realizada a aplicação de uma solução nutritiva comercial contendo $15 \%$ de N, $15 \%$ de $\mathrm{P}_{2} \mathrm{O}_{5}$ e $20 \%$ de $\mathrm{K}_{2} \mathrm{O}$ em igual volume para todos os tratamentos, uma vez por semana.

Aos 30 DAS, foram realizadas as seguintes avaliações: toxicidade visual (utilizando a escala do IAPAR, citado por Pereira \& Bazoni (1995), em que 0\% significa nenhuma injúria e $100 \%$, morte da planta, altura das plantas (cm) e a biomassa seca das raízes e da parte aérea $(\mathrm{g})$.

Todas as características que atenderam às pressuposições de normalidade e homogeneidade das variâncias, pelos testes de Lilliefors e de Cochran, respectivamente, foram submetidas à análise de variância para a verificação de significância dos dois fatores estudados e da interação entre eles pelo teste F. A comparação entre as cultivares de feijão foi feita pelo teste de Tukey, e entre as doses do s-metolachlor, pela análise de regressão. Para a análise de variância com o teste $\mathrm{F}$ e para o teste de Tukey, foi adotado o nível de significância igual a
5\%. Para a análise de regressão, foram adotados os níveis de $1 \%$ ou de $5 \%$ de significância.

\section{RESULTADOS E DISCUSSÃO}

Nas avaliações da altura, biomassa seca da parte aérea (BSPA) e biomassa seca das raízes (BSR) das plantas, observou-se interação significativa entre as cultivares de feijão e as doses do s-metolachlor, ou seja, o comportamento das cultivares variou em relação às doses utilizadas, e o efeito das doses do s-metolachlor foi diferente entre as cultivares. As cultivares de feijão que apresentaram os maiores valores de altura de plantas, para todas as doses testadas do s-metolachlor $(\mathrm{P}<0,05)$, foram a Jalo Precoce e a Vermelho 2157, com exceção da maior dose $(3,84 \mathrm{~kg} / \mathrm{ha})$, em que o Jalo Precoce foi superior (Tabela 2).

Pela Figura 1, verificou-se que a única cultivar que não apresentou diminuição da altura de plantas com o aumento das doses do s-metolachlor foi a Pérola. Mesmo assim, a redução da altura para as outras cultivares foi pequena, com exceção da cultivar Vermelho 2157 , que foi a mais sensível, com redução de $5,1589 \mathrm{~cm}$ da altura de plantas aos 30 DAS, a cada aumento de 1 $\mathrm{kg} / \mathrm{ha}$ aplicado do herbicida (Tabela 3). Segundo Pillai et al. (1979), os herbicidas do grupo das cloroacetamidas, como o s-metolachlor, são inibidores de crescimento, afetando o desenvolvimento da parte aérea e de raízes após a germinação das sementes de plantas suscetíveis.

TABELA 2 - Médias das alturas (cm) de plantas de seis cultivares de feijão aos 30 DAS após a aplicação de várias doses do s-metolachlor.

\begin{tabular}{lccccccc}
\hline \multirow{2}{*}{$\begin{array}{l}\text { Cultivares de } \\
\text { feijão }\end{array}$} & $\mathbf{0}$ & $\mathbf{0 , 4 8}$ & $\mathbf{0 , 9 6}$ & $\mathbf{1 , 4 4}$ & $\mathbf{1 , 9 2}$ & $\mathbf{2 , 8 8}$ & $\mathbf{3 , 8 4}$ \\
\cline { 2 - 8 } & \multicolumn{7}{c}{ Altura (cm) } \\
\cline { 2 - 8 } & $31,58 \mathrm{a}$ & $29,00 \mathrm{a}$ & $27,58 \mathrm{a}$ & $27,75 \mathrm{a}$ & $25,59 \mathrm{a}$ & $25,33 \mathrm{a}$ & $23,75 \mathrm{a}$ \\
Jalo Precoce & $11,08 \mathrm{~b}$ & $10,46 \mathrm{c}$ & $8,75 \mathrm{~b}$ & $8,67 \mathrm{~cd}$ & $7,43 \mathrm{~b}$ & $7,54 \mathrm{~b}$ & $6,58 \mathrm{c}$ \\
Rudá & $10,58 \mathrm{~b}$ & $9,33 \mathrm{c}$ & $9,00 \mathrm{~b}$ & $7,08 \mathrm{~d}$ & $6,54 \mathrm{~b}$ & $5,75 \mathrm{~b}$ & $4,75 \mathrm{c}$ \\
Carioca & $30,50 \mathrm{a}$ & $33,29 \mathrm{a}$ & $32,94 \mathrm{a}$ & $21,33 \mathrm{ab}$ & $30,42 \mathrm{a}$ & $19,83 \mathrm{a}$ & $12,05 \mathrm{bc}$ \\
Vermelho 2157 & $16,50 \mathrm{~b}$ & $17,83 \mathrm{~b}$ & $14,38 \mathrm{~b}$ & $14,50 \mathrm{bc}$ & $13,67 \mathrm{~b}$ & $12,00 \mathrm{~b}$ & $14,67 \mathrm{~b}$ \\
Pérola & $14,75 \mathrm{~b}$ & $13,21 \mathrm{bc}$ & $13,50 \mathrm{~b}$ & $11,75 \mathrm{~cd}$ & $10,58 \mathrm{~b}$ & $9,79 \mathrm{~b}$ & $10,33 \mathrm{bc}$ \\
\hline Xamego & &
\end{tabular}

Médias seguidas por uma mesma letra na coluna não diferem entre si pelo teste de Tukey $(\mathbf{P}>\mathbf{0 , 0 5})$. 


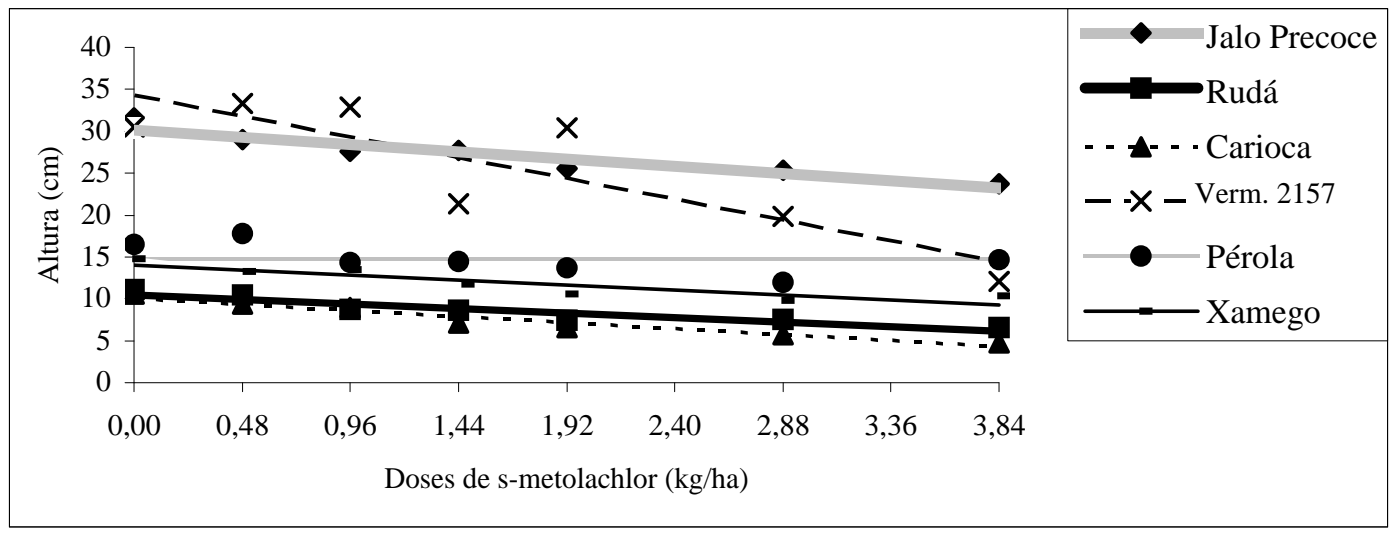

FIGURA 1 - Altura $(\mathrm{cm})$ de plantas de seis cultivares de feijão em resposta a doses de s-metolachlor, aos 30 DAS.

TABELA 3 - Equações de regressões da altura $(\mathrm{cm})$ de plantas de seis cultivares de feijão em resposta a doses de smetolachlor (D).

\begin{tabular}{llc}
\hline \multicolumn{1}{c}{ Cultivares de feijão } & \multicolumn{1}{c}{ Equações de regressões } & $\mathbf{r}^{\mathbf{2}(\%)}$ \\
\hline Jalo Precoce & $\hat{\mathrm{Y}}=30,2217-1,8196^{* *} \mathrm{D}$ & 89,05 \\
Rudá & $\hat{\mathrm{Y}}=10,5047-1,1299^{*} \mathrm{D}$ & 86,73 \\
Carioca & $\hat{\mathrm{Y}}=10,0641-1,5110^{* * \mathrm{D}}$ & 93,68 \\
Vermelho 2157 & $\hat{\mathrm{Y}}=34,2561-5,1589 * * \mathrm{D}$ & 74,05 \\
Pérola & $\overline{\mathrm{Y}}=14,7917$ & - \\
Xamego & $\hat{\mathrm{Y}}=14,0364-1,2447 * \mathrm{D}$ & 81,11 \\
\hline
\end{tabular}

\section{** Significativo pelo teste $t$ ao nível de $1 \%$ de probabilidade.}

* Significativo pelo teste $t$ ao nível de $5 \%$ de probabilidade.

Em relação à avaliação da biomassa seca da parte aérea das plantas (BSPA), a cultivar Jalo Precoce apresentou os maiores valores para todas as doses do smetolachlor testadas $(\mathrm{P}<0,05)$. Apenas a cultivar Pérola quando submetida ao herbicida nas doses de 0,48 e 3,84 $\mathrm{kg} /$ ha apresentou BSPA estatisticamente similar à cultivar Jalo Precoce (Tabela 4). A única cultivar que apresentou redução da BSPA com a aplicação de doses crescentes do s-metolachlor foi a Carioca (Figura 2). Pela análise da Tabela 5, constata-se que cada aumento de 1 $\mathrm{kg} / \mathrm{ha}$ do s-metolachlor aplicado resultou na redução de $0,1765 \mathrm{~g}$ de BSPA por planta da cultivar Carioca aos 30 DAS. Cieslar \& Binning (1974) atribuem as diferenças observadas entre a sensibilidade de cultivares de feijão ao herbicida alachlor (mesmo grupo químico que o s-metolachlor), a variações na translocação do herbicida entre as cultivares.

A cultivar Jalo Precoce apresentou a maior biomassa seca de raízes (BSR) em todas as doses do smetolachlor avaliadas (Tabela 6). Somente as cultivares Carioca e Jalo Precoce mostraram-se suscetíveis ao smetolachlor, quanto à redução da BSR (Figura 3). Contudo, a maior redução foi observada para a cultivar Carioca, na qual cada aumento de $1 \mathrm{~kg} / \mathrm{ha}$ de s-metolachlor aplicado propiciou a diminuição de 0,0568 g de BSR por planta aos 30 DAS (Tabela 7). Para Fuerst (1987), o aumento no metabolismo dos herbicidas do grupo das cloroacetamidas, observado em plantas tolerantes, pode ser atribuído à habilidade dessas espécies em manter altos níveis de glutationa. 
TABELA 4 - Biomassa seca da parte aérea (BSPA) (g) de plantas de seis cultivares de feijão aos 30 DAS após a aplicação de várias doses de s-metolachlor.

\begin{tabular}{lccccccc}
\hline \multirow{2}{*}{$\begin{array}{c}\text { Cultivares de } \\
\text { feijão }\end{array}$} & $\mathbf{0}$ & $\mathbf{0 , 4 8}$ & $\mathbf{0 , 9 6}$ & $\mathbf{1 , 4 4}$ & $\mathbf{1 , 9 2}$ & $\mathbf{2 , 8 8}$ & $\mathbf{3 , 8 4}$ \\
\cline { 2 - 8 } & \multicolumn{7}{c}{ Doses de s-metolachlor $(\mathbf{k g} / \mathbf{h a})$} \\
\hline Jalo Precoce & $1,77 \mathrm{a}$ & $1,32 \mathrm{a}$ & $1,67 \mathrm{a}$ & $1,56 \mathrm{a}$ & $1,63 \mathrm{a}$ & $1,62 \mathrm{a}$ & $1,54 \mathrm{a}$ \\
Rudá & $0,67 \mathrm{c}$ & $0,69 \mathrm{c}$ & $0,53 \mathrm{~b}$ & $0,58 \mathrm{~b}$ & $0,46 \mathrm{c}$ & $0,42 \mathrm{c}$ & $0,54 \mathrm{~b}$ \\
Carioca & $0,81 \mathrm{bc}$ & $0,89 \mathrm{bc}$ & $0,93 \mathrm{~b}$ & $0,72 \mathrm{~b}$ & $0,53 \mathrm{bc}$ & $0,32 \mathrm{c}$ & $0,31 \mathrm{~b}$ \\
Vermelho 2157 & $0,61 \mathrm{c}$ & $0,71 \mathrm{bc}$ & $0,65 \mathrm{~b}$ & $0,58 \mathrm{~b}$ & $0,65 \mathrm{bc}$ & $0,61 \mathrm{bc}$ & $0,47 \mathrm{~b}$ \\
Pérola & $1,16 \mathrm{~b}$ & $1,11 \mathrm{ab}$ & $0,93 \mathrm{~b}$ & $0,89 \mathrm{~b}$ & $0,94 \mathrm{~b}$ & $0,98 \mathrm{~b}$ & $1,14 \mathrm{a}$ \\
Xamego & $0,77 \mathrm{bc}$ & $0,75 \mathrm{bc}$ & $0,82 \mathrm{~b}$ & $0,87 \mathrm{~b}$ & $0,70 \mathrm{bc}$ & $0,65 \mathrm{bc}$ & $0,71 \mathrm{~b}$ \\
\hline
\end{tabular}

Médias seguidas por uma mesma letra na coluna não diferem entre si pelo teste de Tukey $(\mathbf{P}>\mathbf{0 , 0 5})$.

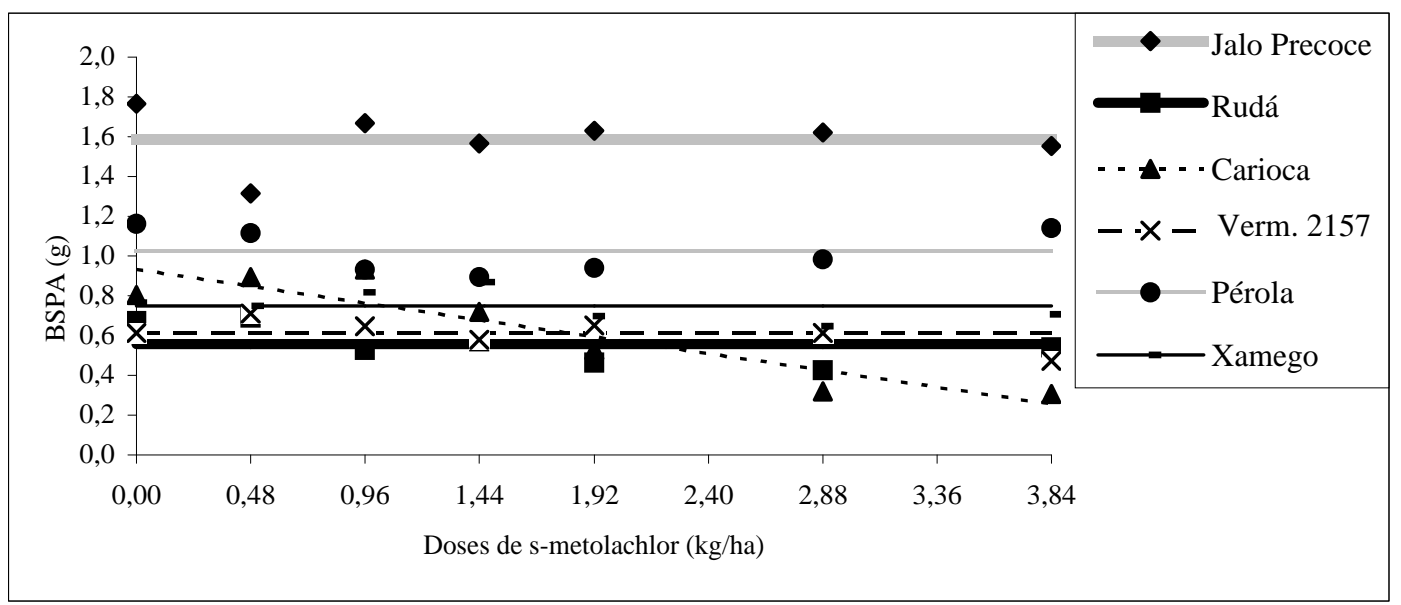

FIGURA 2 - Biomassa seca da parte aérea (BSPA) (g) de plantas de seis cultivares de feijão em resposta a doses de s-metolachlor, aos 30 DAS.

TABELA 5 - Equações de regressões da biomassa seca da parte aérea (BSPA) (g) de plantas de seis cultivares de feijão em resposta a doses de s-metolachlor (D).

\begin{tabular}{llc}
\hline \multicolumn{1}{c}{ Cultivares de feijão } & \multicolumn{1}{c}{ Equações de regressões } & $\mathbf{r}^{\mathbf{2}(\%)}$ \\
\hline Jalo Precoce & $\overline{\mathrm{Y}}=1,5869$ & - \\
Rudá & $\overline{\mathrm{Y}}=0,5572$ & - \\
Carioca & $\hat{\mathrm{Y}}=0,9335-0,1765^{* *} \mathrm{D}$ & 83,95 \\
Vermelho 2157 & $\overline{\mathrm{Y}}=0,6121$ & - \\
Pérola & $\overline{\mathrm{Y}}=1,0243$ & - \\
Xamego & $\overline{\mathrm{Y}}=0,7501$ & - \\
\hline
\end{tabular}

\footnotetext{
** Significativo pelo teste $\mathbf{t}$ ao nível de $1 \%$ de probabilidade.
}

Ciênc. agrotec., Lavras. V.27, n.1, p.150-157, jan./fev., 2003 
TABELA 6 - Biomassa seca das raízes (BSR) (g) de plantas de seis cultivares de feijão aos 30 DAS após a aplicação de várias doses de s-metolachlor.

\begin{tabular}{lccccccc}
\hline \multirow{2}{*}{$\begin{array}{c}\text { Cultivares de } \\
\text { feijão }\end{array}$} & $\mathbf{7}$ & $\mathbf{0 , 4 8}$ & $\mathbf{0 , 9 6}$ & $\mathbf{1 , 4 4}$ & $\mathbf{1 , 9 2}$ & $\mathbf{2 , 8 8}$ & $\mathbf{3 , 8 4}$ \\
\cline { 2 - 8 } & \multicolumn{7}{c}{ Doses de s-metolachlor $(\mathbf{k g} / \mathbf{h a})$} \\
\hline Jalo Precoce & $0,65 \mathrm{a}$ & $0,46 \mathrm{a}$ & $0,58 \mathrm{a}$ & $0,56 \mathrm{a}$ & $0,54 \mathrm{a}$ & $0,53 \mathrm{a}$ & $0,46 \mathrm{a}$ \\
Rudá & $0,18 \mathrm{c}$ & $0,19 \mathrm{~b}$ & $0,15 \mathrm{~b}$ & $0,18 \mathrm{~b}$ & $0,14 \mathrm{~b}$ & $0,12 \mathrm{~b}$ & $0,13 \mathrm{bc}$ \\
Carioca & $0,25 \mathrm{bc}$ & $0,23 \mathrm{~b}$ & $0,29 \mathrm{~b}$ & $0,18 \mathrm{~b}$ & $0,15 \mathrm{~b}$ & $0,08 \mathrm{~b}$ & $0,07 \mathrm{c}$ \\
Vermelho 2157 & $0,21 \mathrm{c}$ & $0,23 \mathrm{~b}$ & $0,17 \mathrm{~b}$ & $0,15 \mathrm{~b}$ & $0,19 \mathrm{~b}$ & $0,23 \mathrm{~b}$ & $0,21 \mathrm{bc}$ \\
Pérola & $0,41 \mathrm{~b}$ & $0,29 \mathrm{~b}$ & $0,24 \mathrm{~b}$ & $0,25 \mathrm{~b}$ & $0,20 \mathrm{~b}$ & $0,23 \mathrm{~b}$ & $0,27 \mathrm{~b}$ \\
Xamego & $0,24 \mathrm{c}$ & $0,20 \mathrm{~b}$ & $0,20 \mathrm{~b}$ & $0,27 \mathrm{~b}$ & $0,20 \mathrm{~b}$ & $0,18 \mathrm{~b}$ & $0,18 \mathrm{bc}$ \\
\hline
\end{tabular}

Médias seguidas por uma mesma letra na coluna não diferem entre si pelo teste de Tukey $(\mathbf{P}>\mathbf{0 , 0 5})$.

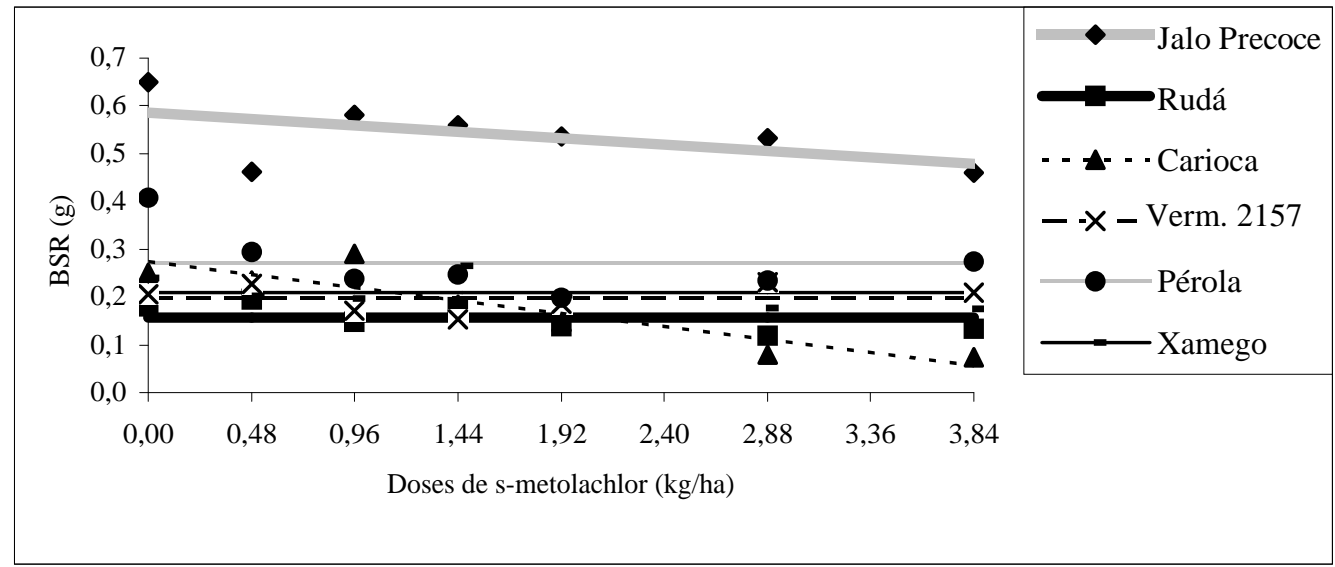

FIGURA 3 - Biomassa seca de raízes (BSR) (g) de plantas de seis cultivares de feijão em resposta a doses de smetolachlor, aos 30 DAS.

TABELA 7 - Equações de regressões da biomassa seca das raízes (BSR) (g) de plantas de seis cultivares de feijão em resposta a doses de s-metolachlor.

\begin{tabular}{llc}
\hline \multicolumn{1}{c}{ Cultivares de feijão } & \multicolumn{1}{c}{ Equações de regressões } & $\mathbf{r}^{2}(\%)$ \\
\hline Jalo Precoce & $\hat{\mathrm{Y}}=0,5863-0,0281 * \mathrm{D}$ & 32,61 \\
Rudá & $\overline{\mathrm{Y}}=0,1564$ & - \\
Carioca & $\hat{\mathrm{Y}}=0,2735-0,0568 * * \mathrm{D}$ & 82,63 \\
Vermelho 2157 & $\overline{\mathrm{Y}}=0,1977$ & - \\
Pérola & $\overline{\mathrm{Y}}=0,2700$ & - \\
Xamego & $\overline{\mathrm{Y}}=0,2084$ & - \\
\hline
\end{tabular}

** Significativo pelo teste $\mathbf{t}$ ao nível de $1 \%$ de probabilidade.

* Significativo pelo teste $\mathbf{t}$ ao nível de $5 \%$ de probabilidade. 
Os resultados dos sintomas visuais da toxicidade do s-metolachlor às cultivares de feijão são apresentados na Tabela 8. Todas as cultivares apresentaram aumento no nível de sintomas visuais de toxicidade com o aumento das doses do s-metolachlor (Figura 4). As cultivares Carioca e Vermelho 2157 mostraram-se como as mais sensíveis à ação do s-metolachlor, apresentando, respectivamente, aumentos de 22,0497 e 21,1140\% nas injúrias das plantas aos 30 DAS, a cada aumento de $1 \mathrm{~kg} / \mathrm{ha}$ de s-metolachlor aplicado (Tabela 9). Analisando-se a toxicidade apresentada na dose média comercial do smetolachlor recomendada pela empresa fabricante $(0,96$ $\mathrm{kg} / \mathrm{ha}$ ) (Tabela 8), percebeu-se que o nível de toxicidade nas plantas da cultivar Carioca foi, em média, de 35\%, sendo esse valor já considerado de difícil aceitação por parte dos produtores (Pereira \& Bazoni, 1995). Resultado que difere do encontrado por Machado Neto et al. (1988), os quais observaram leve toxicidade do metolachlor à cultivar de feijão Carioca. As cultivares mais tolerantes ao smetolachlor quanto à exteriorização de sintomas de toxicidade foram a Pérola e a Jalo Precoce. Os sintomas de toxicidade do s-metolachlor observados nas cultivares de feijão foram redução do internódio, enrugamento das folhas e fusão das margens das folhas, concordando com os sintomas descritos por Van Rensburg \& Van Dyk (1986), para o metolachlor em plantas de feijão.

TABELA 8 - Toxicidade $(\%)$ em plantas de seis cultivares de feijão aos 30 DAS após a aplicação de várias doses de s-metolachlor.

\begin{tabular}{cccccccc}
\hline \multirow{2}{*}{$\begin{array}{c}\text { Cultivares de } \\
\text { feijão }\end{array}$} & $\mathbf{0}$ & $\mathbf{0 , 4 8}$ & $\mathbf{0 , 9 6}$ & $\mathbf{1 , 4 4}$ & $\mathbf{1 , 9 2}$ & $\mathbf{2 , 8 8}$ & $\mathbf{3 , 8 4}$ \\
\cline { 2 - 7 } & & & \multicolumn{7}{c}{ Toxicidade (\%) } \\
\hline Jalo Precoce & 0 & 10 & 10 & 15 & 25 & 30 & 40 \\
Rudá & 0 & 10 & 15 & 25 & 45 & 65 & 65 \\
Carioca & 0 & 30 & 35 & 55 & 60 & 80 & 90 \\
Vermelho 2157 & 0 & 15 & 15 & 40 & 45 & 65 & 80 \\
Pérola & 0 & 10 & 20 & 20 & 20 & 50 & 30 \\
Xamego & 0 & 0 & 5 & 15 & 35 & 45 & 50 \\
\hline
\end{tabular}

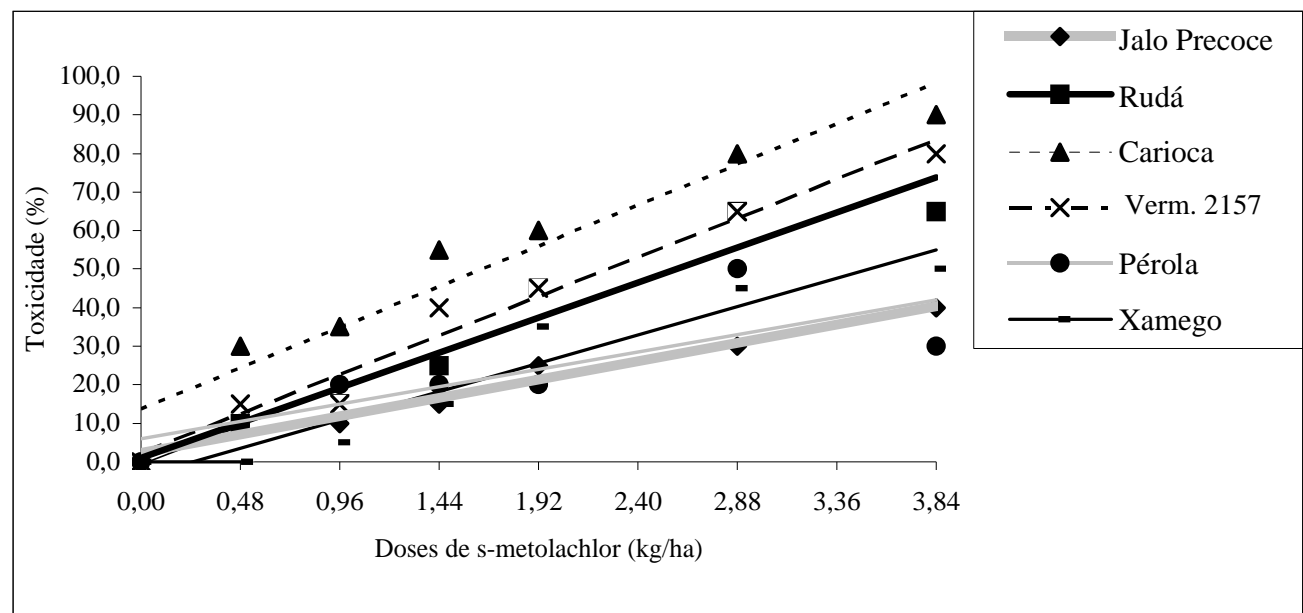

FIGURA 4 - Toxicidade (\%) em plantas de seis cultivares de feijão em resposta a doses de s-metolachlor, aos 30 DAS. 
TABELA 9 - Equações de regressões da toxicidade (\%) de plantas de seis cultivares de feijão em resposta a doses de s-metolachlor.

\begin{tabular}{lll}
\hline \multicolumn{1}{c}{ Cultivares de feijão } & \multicolumn{1}{c}{ Equações de regressões } & $\mathbf{r}^{\mathbf{2}(\boldsymbol{\%})}$ \\
\hline Jalo Precoce & $\hat{\mathrm{Y}}=2,0958+10,0112^{* *} \mathrm{D}$ & 97,01 \\
Rudá & $\hat{\mathrm{Y}}=0,9880+18,9309^{* *} \mathrm{D}$ & 93,96 \\
Carioca & $\hat{\mathrm{Y}}=13,7126+22,0497 * * \mathrm{D}$ & 92,95 \\
Vermelho 2157 & $\hat{\mathrm{Y}}=2,3952+21,1140^{* *} \mathrm{D}$ & 97,18 \\
Pérola & $\hat{\mathrm{Y}}=5,9281+9,4187 * \mathrm{D}$ & 65,64 \\
Xamego & $\hat{\mathrm{Y}}=-3,7725+15,3131^{* *} \mathrm{D}$ & 92,54 \\
\hline
\end{tabular}

** Significativo pelo teste $t$ ao nível de $1 \%$ de probabilidade.

* Significativo pelo teste $\mathbf{t}$ ao nível de $5 \%$ de probabilidade.

\section{CONCLUSÕES}

A cultivar de feijão Vermelho 2157 foi a mais afetada em relação à altura de plantas com o aumento das doses do s-metolachlor. Com o aumento das doses do smetolachlor, houve redução da biomassa seca da parte aérea de plantas de feijão, somente para a cultivar Carioca. O aumento das doses do s-metolachlor reduziu a biomassa seca das raízes de plantas de feijão das cultivares Carioca e Jalo Precoce. As cultivares Carioca e Vermelho 2157 apresentaram os maiores níveis de toxicidade com a aplicação do s-metolachlor. A cultivar Pérola foi a mais seletiva ao s-metolachlor.

\section{REFERÊNCIAS BIBLIOGRÁFICAS}

CIESLAR, R., BINNING, L. K. Translocation of ${ }^{14} \mathrm{C}$ alachlor in lima beans as related to phytotoxicity. In: NORTH CENTRAL WEED CONTROL CONFERENCE, 29., 1974, Madison. Proceedings... Madison: University of Wisconsin, 1974. p. 32-33.

EMPRESA BRASILEIRA DE PESQUISA AGROPECUÁRIA - EMBRAPA. Centro Nacional de Pesquisa de Solos. Manual de métodos de análise de solo. 2 ed. Rio de Janeiro, 1997. 212 p.

FUENTES, J. R., SILVA, J. F., VIEIRA, C., CONDÉ, A. R. Tolerância de cultivares de feijão (Phaseolus vulgaris L.) aos herbicidas alachlor e linuron. Revista Ceres, Viçosa, v. 31, n. 174, p. 136-145, 1984.

FUERST, E. P. Understanding the mode of action of the chloroacetamide and thiocarbamate herbicides. Weed Technology, Champaign, v. 1, n. 4, p. 270-277, 1987.

MACHADO NETO, G. J., SÁ, M. E., ALMEIDA, M. R. Seletividade de herbicidas a cultivares de feijão (Phaseo- lus vulgaris L.) e eficiência no controle das plantas daninhas. In: CONGRESSO BRASILEIRO DE HERBICIDAS E PLANTAS DANINHAS, 17., 1988, Piracicaba. Resumos... Piracicaba: SBHED, 1988. p. 249250 .

O’CONNELL, P. J., HARMS, C. T., ALLEN, J. R. F. Metolachlor, s-metolachlor and their role within sustainable weed-management. Crop Protection, Surrey, v. 17, n. 3, p. 207-212, 1998.

PEREIRA, F. A. R.; BAZONI, R. Avaliação de herbicidas na cultura da soja em áreas de cerrado de Mato Grosso do Sul. Campo Grande: EMPAER, 1995. 38 p. (EMPAER-MS. Documento 45).

PILLAI, P., DAVIS, D. E., TRUELOVE, B. Effects of metolachlor on germination, growth, leucine uptake, and protein synthesis. Weed Science, Champaign, v. 27, n. 6, p. 634-637, 1979.

RODRIGUES, B. N., ALMEIDA, F. S., OLIVEIRA, V. F. Utilização de trifluralin em pré-emergência e de novas formulações de alachlor e metolachlor na cultura do feijão. In: CONGRESSO BRASILEIRO DE HERBICIDAS E PLANTAS DANINHAS, 15.; CONGRESSO DE LA ASOCIACIÓN LATINOAMERICANA DE MALEZAS, 7., 1984, Belo Horizonte. Resumos... Belo Horizonte: SBHED, 1984. p. 57-58.

VAN RENSBURG, E., VAN DYK, L. P. The persistence in soil and phytotoxicity on dry beans of alachlor and metolachlor as affected by climatic factors. South Africa Journal of Plant Soil, v. 3, n. 3, p. 9598, 1986. 